\section{ETHICS WATCH}

\section{Did eugenics ever die?}

Classical eugenics, as a coercive government-sponsored programme to control reproduction for the betterment of humankind, might be dead. However, eugenic thinking survives, especially in Eastern Europe, India, China and other developing nations, as evidenced by the directively pessimistic construction of genetic counselling. The ethical norm for counselling, which was established in North America and the United Kingdom when memories of the 1930s Eugenics Movement were still fresh, is 'non-directiveness', which entails providing information in as unbiased a manner as possible and supporting people in making their own decisions. However, in a recent survey of clinical geneticists in 36 nations, it was found that - except in North America, the United Kingdom and parts of Northern Europe - the norm is for genetic counsellors to provide 'directive pessimism', which is best described as the urging of abortion or the presentation of purposively slanted information (Wertz 1998). In nations with an inadequate social infrastructure to support those with disabilities (including India and China, where total expenditure on public health is US\$ 10 per person, annually), pessimistic counselling could be seen as realistic counselling. But, in view of a worldwide trend towards increased respect for people, aren't people entitled to unbiased information?

When the Human Genome Project (HGP) was launched, scientists hoped that one of its applications would be the prevention, perhaps even the elimination, of 'birth defects'. This sounds laudable, until one tries to define which 'defects' need to be eliminated. Do these include cleft lip (considered serious and not treated, for economic reasons, in some countries), homosexuality, obesity (in the absence of a known genetic syndrome), Turner syndrome and deafness? 'Birth defects' are often culturally defined. Even genetics professionals don't agree on what constitutes a 'serious' disorder. Most of the 600 conditions listed by 1,400 geneticists in one survey appeared in both 'serious' and 'not serious' categories (Wertz \& Knoppers 2002). What professionals did agree on was that families should make their own definitions. However, if everybody makes the same definitions, private decisions - for example, in favour of male gender - could become a social problem; vibrant communities (such as the deaf community) could disappear; 'prevention' could blur into enhancement. Sometimes science has unintended uses. For example, the main use of adult genetic testing is to establish paternity and, in some countries, prenatal diagnosis is most often used to select for fetuses of a particular gender.

Is the goal of the HGP disease prevention? Or is it empowering people to make informed decisions, even if these decisions are not 'preventive'? Or should the goal be to improve humankind by enhancing immunity or intelligence, something we already do by socially approved means that are not always equally available to all, such as by vaccination or private

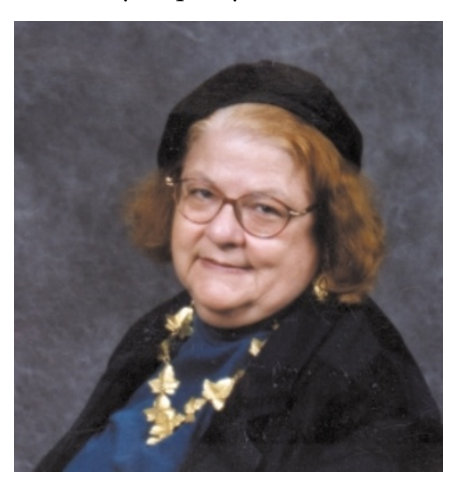

schooling? Whatever the goal, it is important to remember that genetics cannot solve all human health problems. Poverty, malnutrition, illiteracy, war and oppression of women also contribute greatly to ill health. Dorothy C. Wertz

REFERENCES Wertz, D. C. Eugenics is alive and well: a survey of genetic professionals around the world. Science in Context 11, 493-510 (1998) | Wertz D. C. \& Knoppers, B. M. Serious genetic Wertz, D. C. \& Knoppers, B. M. Serious genetic disorders: can or should they be defined? Am. J. Med. Genet. 108, 29-35 (2002)
BEHAVIOURAL GENETICS

\section{Dipsomaniac mice?}

Worried about that deadline you have to meet? Fancy a beer to help you cope with stress? This reaction might seem exclusive to humans but, as a recent paper in Science shows, something similar is observed in mice that lack a receptor for corticotropinreleasing hormone (CRH).

Alcoholism depends on both environmental and genetic factors. It is well known that stress can have a profound influence on alcohol intake, and some studies have implicated the CRH system in stress-induced alcohol drinking. Sillaber et al. followed this lead and measured voluntary alcohol intake in mice lacking the $\mathrm{CRH}$ receptor (Crhr1), testing whether stress had any effect on drinking behaviour. They found that, under basal conditions, the knockout mice did not drink more alcohol than their wild-type littermates. However, after repeated stress, the knockout mice started to drink more alcohol on a regular basis. Intriguingly, this behavioural change was not observed immediately after the stressful events; it developed gradually over several weeks and lasted for at least six months, even when the animals were not confronted with any further stressful experience.

As glutamate-mediated neurotransmission has also been implicated in stress-induced alcohol drinking, Sillaber $e t$ al. looked for changes in this system that might help to explain the behavioural response of the knockout mice. They found that the NMDA ( $N$-methyl-D-aspartate) receptor subunit $\mathrm{Nr} 2 \mathrm{~b}$ was upregulated in the hippocampus and nucleus accumbens of these animals, structures that are part of the memory and reward circuits of the brain, respectively.

The results of Sillaber et al. point to Crhr1 and $\mathrm{Nr} 2 \mathrm{~b}$ as possible risk factors for alcoholism, but they actually raise more questions than they answer. Why does stress elicit such a delayed effect on alcohol intake, instead of an immediate behavioural reaction? Given that the stress response of the knockout animals is reduced, why does the absence of Crhr1 increase their susceptibility to stress-induced alcohol intake, instead of decreasing it? More importantly, do these knockout animals constitute an ideal model of alcoholism? I'll have another drink before joining the authors to ponder these questions.

Juan Carlos López, Editor Nature Reviews Neuroscience

69) References and links

ORIGINAL RESEARCH PAPER Sillaber, I. et al. Enhanced and delayed stress-induced alcohol drinking in mice lacking functional CRH1 receptors. Science 296, 931-933 (2002) FURTHER READING Weiss, F. \& Porrino, L. J. Behavioural neurobiology of alcohol addiction: recent advances and challenges. J. Neurosci. 22, 3332-3337 (2002) WEB SITE

Encyclopedia of Life Sciences: http://www.els.net Alcoholism 